Lee, S.-L. (2019). Predicting SNS addiction with the Big Five and the Dark Triad. Cyberpsychology: Journal of Psychosocial Research on Cyberspace, 13(1), article 3. http://dx.doi.org/10.5817/CP2019-1-3

\title{
Predicting SNS addiction with the Big Five and the Dark Triad
}

\author{
Soon-Li Lee \\ School of Liberal Arts \& Sciences, Faculty of Social Sciences \& Leisure Management, Taylor's University Lakeside Campus \& \\ Jeffrey Cheah School of Medicine and Health Sciences, Monash University Malaysia, Subang Jaya, Malaysia
}

\begin{abstract}
A considerable amount of literature has widely discussed the issue in regard to the prediction of social networking sites (SNS) addiction with personality traits. One of the existing issues is the small effect sizes that showed that the traits outlined by the Five-Factor model are lacking the required specificity to predict specific behaviours such as SNS addiction. In light of this issue, the present research attempted to predict SNS addiction with the Dark Triad traits that have been linked to impulsivity that is central to the development of SNS addiction. In this study, a sample of 204 (Male $=77,38 \%$; Female $=124,60 \%$; Not mentioned $=3,2 \% ; M_{\text {age }}=22.94, S_{\text {age }}=3.43$ ) university students in Malaysia completed the Big Five Inventory, the Short Dark Triad, and the adapted Bergen Facebook Addiction Scale. Results indicated that SNS addiction was significantly predicted by the measured psychopathy of the Dark Triad. In predicting SNS addiction, the inclusion of the Dark Triad traits contributed significant amount of variance after controlling the Five-Factor model. Finally, the implications of the results were discussed in this manuscript.
\end{abstract}

Keywords: Social network sites; SNS addiction; the Big Five personality; the Dark Triad

\section{Introduction}

Social network sites (SNS) are web-based applications that enable users to construct personal profiles with the purpose of regulating and maintaining contacts online (boyd \& Ellison, 2007). One of the issues of SNS is described as the failure to regulate SNS usages that lead to negative outcomes (Andreassen \& Pallesen, 2014; LaRose, Kim, \& Peng, 2010), commonly known as SNS addiction. Existing research revealed the detrimental effects of SNS addiction on several domains of functioning that include well-being (Koc \& Gulyagci, 2013), interpersonal relationships (Elphinston \& Noller, 2011) as well as self-esteem and life satisfaction (Błachnio, Przepiorka, \& Pantic, 2016).

According to Andreassen and Pallesen (2014), personality is an important factor in the development of SNS addiction. In the literature, research that intends to identify personality traits that are indicative of the risk of SNS addiction often operationalized personality with the Five-Factor model. The Five-Factor model consists of five broad domains known as Extraversion that refers to the tendency to seek for companionship from others, Neuroticism that refers to the tendency to experience negative emotions, Conscientiousness that refers to the tendency to be organized, Openness to Experience that refers to the tendency to expose oneself to new stimulus or experience, and Agreeableness that refers to the tendency to be cooperative with others (Benet-Martinez \& John, 1998; John, Donahue, \& Kentle, 1991). According to existing research, there are several indicators of the risk of SNS addiction, which include high Extraversion (Andreassen, Torsheim, Brunborg, \& Pallesen, 2012; Wang, Ho, Chan, \& Tse, 2015; Wilson, Fornasier, \& White, 2010), high Neuroticism (Caci, Cardaci, Scrima, \& Tabacchi, 2017; Wang et al., 2015), low Conscientiousness (Andreassen et al., 2013; Błachnio \& Przepiorka, 2016a; Wilson et al., 2010), and low Openness to Experience (Andreassen et al., 2013; Błachnio \& Przepiorka, 2016a). However, these 
traits accounted for a small amount of variance even though the findings supported the significance of these traits in predicting SNS addiction. For instance, Wilson et al. (2010) found that the broad five domains significantly predicted addictive tendencies toward SNS with $8.5 \%$ of the variance while Błachnio and Przepiorka (2016a) found that these domains accounted for $6 \%$ of the variance. Hence, this illustrates the limited contribution of these traits in predicting SNS related behaviours (Amichai-Hamburger \& Vinitzky, 2010; Ross et al., 2009). Alternatively, the small amount of variance accounted by the Five-Factor model traits implies that these traits have insufficient specificity to predict specific behaviours (Hough, 1992; McAdams, 1992). As a result, it is necessary for researchers to consider other theories of personality to predict the usage of SNS (Ross et al., 2009; Skues, Williams, \& Wise, 2012).

It was demonstrated that subclinical personality traits can be indicative of behavioural addiction. Research suggests that users that are addicted to the internet are more likely to exhibit the characteristics of borderline personality disorder (Dalbudak, Evren, Aldemir, \& Evren, 2014). Similarly, users with high degree of callousness or lack of empathy are prone to internet addiction (Trumello, Babore, Candelori, Morelli, \& Bianchi, 2018). In relation to SNS usages, the facilitating role of narcissism has been supported by research findings (e.g. Buffardi \& Campbell, 2008). The inclusion of narcissism contributed significantly to the predictive model of SNS usages after accounting for Extraversion (Ong et al., 2011), indicating that the measured Extraversion did not account entirely for the measured usages of SNS. In addition, recent findings extend that individuals with elevated self-centeredness are prone to SNS addiction due to the urge to gratify their needs for affiliation and selfassurance (Andreassen, Pallesen, \& Griffiths, 2017; Casale, Fioravanti, \& Rugai, 2016). However, the effect size of .06 indicates that narcissism is weakly correlated with SNS addiction (Andreassen et al., 2017). Additionally, the small effect size accounted by narcissism after controlling for Extraversion (Ong et al., 2011) suggests the need to further explore the role of other related traits in predicting SNS usages. In this case, the present research aims to explore the relationships of SNS addiction and the three aversive traits of the Dark Triad, namely narcissism, psychopathy, and Machiavellianism (Paulhus \& Williams, 2002). Narcissism is marked by a sense of entitlement, dominance and a grandiose self-view (Raskin \& Terry, 1988). Machiavellianism refers to the tendency to manipulate others for own gain (Christie \& Geis, 1970). Psychopathy consists of the lack of empathy, callousness, and erratic behaviours (Hare, 2003). These three aversive traits form the Dark Triad that has been linked to several negative outcomes such as interpersonal difficulties (Stead, Fekken, Kay, \& McDermott, 2012), impulsivity (Crysel, Crosier \& Webster, 2013; Jonason \& Tost, 2010; Jones \& Paulhus, 2011a; Malesza \& Ostaszewski, 2016), clinical psychopathy (Jones \& Figueredo, 2013) and sadism (Chabrol, van Leeuwen, Rodgers, \& Séjourné, 2009). Apart from that, recent research on the Dark Triad has associated these traits with online behaviours such as cyber-aggression (Pabian, De Backer, \& Vandebosch, 2015), problematic online gaming (Kircaburun, Jonason, \& Griffiths, 2018a), cyberstalking (Kircaburun, Jonason, \& Griffiths, 2018b), cyberbullying (Goodboy \& Martin, 2015; Kircaburun et al., 2018b), and online deception or cybertrolling (Buckels, Trapnell, \& Paulhus, 2014; Kircaburun et al., 2018b).

Research extends that certain features on SNS, such as status updates (Garcia \& Sikström, 2014) and selfies (Fox \& Rooney, 2015; McCain et al., 2016), appeal to users with salient features of the Dark Triad. Hence, they tend to exploit these features, which could be a possible cause to their frequent (Fox \& Rooney, 2015) and intense use of SNS (Pabian et al., 2015). It was indicated that frequent use of SNS may escalate into addiction (Hong, Huang, Lin, \& Chiu, 2014) when users are unable to restraint the use of SNS (Błachnio \& Przepiorka, 2016b). Recent findings support the link of the Dark Triad and problematic use of SNS (Kircaburun, Demetrovics, \& Tosuntaş, 2018; Kircaburun et al., 2018b), suggesting that the escalation of prolonged (Fox \& Rooney, 2015) and intense use of SNS (Pabian et al., 2015) into SNS addiction is possible through poor self-control and high degree of impulsivity that are evident amongst those with salient features of the Dark Triad (Crysel et al., 2013; Jonason \& Tost, 2010; Jones \& Paulhus, 2011a; Malesza \& Ostaszewski, 2016). Each of the Dark Triad traits significantly correlated with problematic use of SNS, with psychopathy formed the weakest relationship (Kircaburun, Demetrovics, \& Tosuntas, 2018; Kircaburun et al., 2018b). However, psychopathy has been consistently linked to poor self-control and impulsivity (Jonason \& Tost, 2010; Jones \& Paulhus, 2011a) that are central to the development of SNS addiction (Błachnio \& Przepiorka, 2016b). Reflecting from this, the present research anticipates the significance of psychopathy in predicting SNS addiction.

In addition, the purpose of adopting the Dark Triad traits is to address the limited influence of the Five-Factor model in predicting SNS addiction. It was previously indicated that the Five-Factor model does not reflect adequately on human personality (Veselka, Schermer, \& Vernon, 2011; Veselka, Schermer, \& Vernon, 2012). Consistent with this argument, a research found that the employment of the Dark Triad traits accounted for 
additional variance in predicting social values after controlling the Five-Factor model (Kajonius, Persson, \& Jonason, 2015). This suggests that the influence exerted by the Dark Triad traits are independent of the Five-Factor model (Carter, Campbell, \& Muncer, 2014).

One of the objectives of the present research is to examine the significance of the Dark Triad traits in predicting SNS addiction. The present research hypothesizes the significance of psychopathy in predicting SNS addiction considering that psychopathy is associated with poor self-control and impulsivity (Jonason \& Tost, 2010; Jones \& Paulhus, 2011a). The next objective of this research is to compare the variances accounted by the Dark Triad and the Five-Factor model in the prediction of SNS addiction. Hence, the present research hypothesizes that the Dark Triad traits will account for additional variance in predicting SNS addiction after controlling the Five-Factor model.

\section{Method}

\section{Participants}

The sample of the present research consisted of 204 undergraduate students in Malaysia. They were all Malaysians, aged between 18 and $27\left(M_{\text {age }}=22.94, S D_{\text {age }}=3.43\right)$. In the demographic aspect, majority of the participants were female (Male $=77,38 \%$; Female $=124,60 \%$; Not mentioned $=3,2 \%$ ), and majority of the participants were identified as Chinese (Malay $=79,39 \%$; Chinese $=99,49 \%$; Indian $=8 ; 4 \%$; Others $=18,8 \%$ ).

\section{Procedure}

The present research was advertised at a university's lecture halls. Those who were interested contacted the researcher for further arrangement to complete the survey questionnaire. They were invited to complete the survey questionnaire in a classroom specifically booked for data collection. Informed consents from the participants were not obtained to ensure anonymity, and no monetary reward was offered to the participants. In this research, data analysis was conducted using SPSS 19. Ethical clearance was granted by the Monash University Human Research Ethics Committee.

\section{Measures}

Demographics . The demographic details of the participants that include age, gender, and ethnicity were obtained at the beginning of the questionnaire.

Big Five personality traits. The traits of the Five-Factor model were measured using the Big Five Inventory (BFI; Benet-Martinez \& John, 1998; John et al., 1991). It consists of 44 items that reflect on five dimensions, namely Openness to Experience (e.g., "I am someone who is curious about many different things"), Conscientiousness (e.g., "I am someone who is dependable, steady"), Extraversion (e.g., "I am someone who is outgoing, sociable"), Agreeableness (e.g., "I am someone who is compassionate, has a soft heart"), and Neuroticism (e.g., "I am someone who is moody, has up and down mood swings"). In the present research, these items were rated on a five-point Likert scale ( 1 = Very inaccurate, 5 = Very accurate $)$. Each factor was formed by summing the corresponding items. The measured five factors exhibited acceptable and high internal consistencies (Extraversion's $a=.71$, Agreeableness' $a=.72$, Conscientiousness' $a=.72$, Neuroticism's $a=.79$, Openness to Experience's $a=.67$ ).

The Dark Triad traits. In the present research, the Dark Triad traits were measured using the Short Dark Triad (SD3; Jones \& Paulhus, 2014). It consists of 27 items that reflect on the three aversive traits, namely psychopathy (e.g., "I like to get revenge on authorities"), Machiavellianism (e.g., "It's not wise to tell your secrets"), and narcissism (e.g., "People see me as a natural leader"). These items were rated on a five-point Likert scale (1 = Strongly disagree, $5=$ Strongly agree). Each subscale was formed by summing the corresponding items. The measured traits exhibited acceptable and high internal consistencies (psychopathy's $\alpha=.75$; Machiavellianism's $\alpha=.65$; narcissism's $\alpha=.66$ ).

SNS addiction. SNS addiction was measured using the Bergen Facebook Addiction Scale (Andreassen et al., 2012). In the present research, the items were rephrased to ensure that they are suitable for the SNS contexts. This measure consists of six items that were rated on a five-point Likert scale $(1=$ Very rarely, $5=$ Very often $)$. A sample 
item of this measure is "How often during the last year have you spent more time on SNS than initially intended?". The items were summed to form the score for SNS addiction. This measure exhibited high internal consistency (SNS addiction's $\alpha=.85$ ).

\section{Results}

Table 1 summarizes the descriptive statistics and the correlation coefficients. The results indicated that the correlations ranged from small to moderate, indicating that multicollinearity was not a concern. The VIF values ranged from $1-2.15$, with the highest value exhibited by the measured psychopathy. The maximum VIF value of 2.15 does not exceed 10, which further support that multicollinearity was not an issue (Kennedy, 1992). From Table 1 , SNS addiction was significantly correlated with psychopathy. The positive correlation suggests that higher degree of psychopathy increases the risk of SNS addiction. In addition, Neuroticism was positively correlated with SNS addiction, which indicates that individuals with poor emotional stability are susceptible to SNS addiction. Agreeableness, Conscientiousness, and Openness to Experience were negatively correlated with SNS addiction.

Table 1. Descriptive Statistics and Correlation Coefficients.

\begin{tabular}{|c|c|c|c|c|c|c|c|c|c|c|}
\hline Variables & $M(S D)$ & 1 & 2 & 3 & 4 & 5 & 6 & 7 & 8 & 9 \\
\hline 1.Extraversion & $24.09(4.42)$ & 1 & .08 & .10 & $-.28 * \star$ & .08 & .03 & $-.14^{\star}$ & $.39 * \star$ & -.05 \\
\hline 2.Agreeableness & $32.04(4.68)$ & _- & 1 & $.39 * *$ & $-.35^{\star \star}$ & $.15^{*}$ & $-.54 * \star$ & $-.17 *$ & -.13 & $-.18 * *$ \\
\hline 3.Conscientiousness & $28.23(4.87)$ & - & _ & 1 & $-.39 * *$ & $.14^{*}$ & $-.27 * \star$ & -.08 & .10 & $-.19 * *$ \\
\hline 4.Neuroticism & $24.86(5.03)$ & - & _ & _ & 1 & -.04 & .17 & $.16^{\star}$ & $-.16^{\star}$ & $.18^{*}$ \\
\hline 5.Openness to Experience & $34.09(4.53)$ & - & - & - & - & 1 & .09 & .08 & $.15^{\star}$ & $-.14^{*}$ \\
\hline 6.Psychopathy & $21.96(5.45)$ & - & - & _ & - & - & 1 & $.43^{* \star}$ & $.32 * \star$ & $.25^{\star \star}$ \\
\hline 7.Machiavellianism & $30.69(5.86)$ & - & - & - & - & - & - & 1 & $.23 * *$ & .11 \\
\hline 8.Narcissism & $25.12(4.75)$ & _ & _- & _ & _ & _ & _- & _ & 1 & .07 \\
\hline 9.SNS addiction & $15.18(5.27)$ & _ & _- & - & _ & _- & _- & _ & _- & 1 \\
\hline
\end{tabular}

Note: $p<.05,{ }^{* \star} p<.001$

Table 2. Hierarchical Regression Predicting SNS Addiction with Demographics and Personality Factors.

\begin{tabular}{|c|c|c|c|c|c|c|c|c|c|c|c|c|}
\hline \multirow[b]{2}{*}{ Variables } & \multicolumn{4}{|c|}{ First step } & \multicolumn{4}{|c|}{ Second step } & \multicolumn{4}{|c|}{ Third step } \\
\hline & $\beta$ & B & SE & $T$ & $\beta$ & B & SE & $t$ & $\beta$ & B & SE & $t$ \\
\hline \multicolumn{13}{|l|}{ Demographics } \\
\hline Age & $-.14 *$ & $-.26^{\star}$ & 1.10 & $-2.37 \star$ & $-.15^{\star}$ & $-.22 *$ & 1.09 & $-.21 *$ & $-.14^{*}$ & $-.22^{\star}$ & .10 & $-2.03^{*}$ \\
\hline Gender & $-.16 *$ & $-1.57 *$ & 7.76 & $-2.03 *$ & $-1.7 *$ & $-1.88 *$ & .78 & $-.24 *$ & $-.17 *$ & $-1.88^{*}$ & .82 & $-1.63^{*}$ \\
\hline \multicolumn{13}{|l|}{ Five-Factor Model } \\
\hline Extraversion & & & & & -.02 & -.02 & .08 & -.26 & -.06 & -.07 & .09 & -.78 \\
\hline Agreeableness & & & & & -.11 & -.12 & .09 & -1.36 & .02 & .02 & .10 & .19 \\
\hline Conscientiousness & & & & & -.06 & -.06 & .08 & -.78 & -.05 & -.05 & .08 & -.61 \\
\hline Neuroticism & & & & & .09 & .09 & .08 & 1.10 & .09 & .09 & .08 & 1.10 \\
\hline Openness to Experience & & & & & $-.16^{\star}$ & $-.18^{*}$ & .08 & $-2.26^{\star}$ & $-.20 *$ & $-.23^{\star}$ & .08 & $-.277^{\star}$ \\
\hline \multicolumn{13}{|l|}{ Dark Triad } \\
\hline Psychopathy & & & & & & & & & $.23 * *$ & $.22 * \star$ & .09 & $2.25 * *$ \\
\hline Machiavellianism & & & & & & & & & -.03 & -.03 & .07 & -.41 \\
\hline \multirow[t]{5}{*}{ Narcissism } & & & & & & & & & .04 & .04 & .09 & .51 \\
\hline & \multirow{4}{*}{\multicolumn{4}{|c|}{$\begin{array}{l}F(2,188)=4.87 * \\
R^{2}=.05 \\
\text { Adjusted } R^{2}=.04\end{array}$}} & \multicolumn{4}{|c|}{$F(7,183)=3.88^{* *}$} & \multicolumn{4}{|c|}{$F(10,180)=3.41 * *$} \\
\hline & & & & & \multicolumn{4}{|c|}{$R^{2}=.13$} & \multicolumn{4}{|c|}{$R^{2}=.16$} \\
\hline & & & & & \multirow{2}{*}{\multicolumn{4}{|c|}{$\begin{array}{l}R^{2} \text { change }=.08^{*} \\
\text { Adjusted } R^{2}=.09\end{array}$}} & \multirow{2}{*}{\multicolumn{4}{|c|}{$\begin{array}{l}R^{2} \text { change }=.03 * * \\
\text { Adiusted } R^{2}=11\end{array}$}} \\
\hline & & & & & & & & & & & & \\
\hline
\end{tabular}

Note: ${ }^{*} p<.05,{ }^{\star}{ }^{*} p<.001 ;{ }^{a}(0=$ Male, $1=$ Female $)$

Hierarchical regression with three blocks was conducted. The results of this regression are summarized in Table 2. The first block consisted of the age and gender of the participants, followed by the Five-Factor model, and finally, the Dark Triad. From Table 2, the initial block accounted for $5 \%\left(R^{2}\right)$ of the variance. The entry of the Five-Factor model contributed $8 \%\left(R^{2}\right)$ of the variance, and the entry of the Dark Triad contributed an additional 3\% $\left(R^{2}\right)$ of the 
variance. The inclusion of the Dark Triad traits significantly contributed to the predictive model, suggesting that the Five-Factor model did not exhaust the variance in the prediction of SNS addiction. SNS addiction was significantly predicted by psychopathy, suggesting that greater degree of psychopathy increases vulnerability towards SNS addiction. Additionally, the Openness to Experience negatively predicted SNS addiction, which implies that individuals with high openness are less likely to develop SNS addiction. Overall, the predictors involved in this study accounted for $16 \%\left(R^{2}\right)$ of the variance.

\section{Discussion}

The present research intended to examine the significance and the contribution of the Dark Triad in predicting SNS addiction. The hypothesized significance of the measured psychopathy as a predictor of SNS addiction was supported. The secondary psychopathy measured in the present research (see Jones \& Paulhus, 2014) has been linked to risky decision-making (e.g. Dean et al., 2013), poor inhibition and high impulsivity (Jonason \& Tost, 2010; Jones \& Paulhus, 2011a; Jones \& Paulhus, 2011b; Malesza \& Ostaszewski, 2016) that will induce excessive use of SNS or SNS addiction (Błachnio \& Przepiorka, 2016b). Therefore, the findings of the present research suggested that high degree of secondary psychopathy elevate the risk of SNS addiction. The findings of the present research indicated that the traits of narcissism and Machiavellianism were not significant predictors of SNS addiction even though previous research found that frequent (Fox \& Rooney, 2015) and intense use of SNS (Pabian et al., 2015) were significantly correlated to these traits. Hence, this highlighted the importance of psychopathy as the only significant predictor of SNS addiction due to its conceptual link with impulsivity (Jones \& Paulhus, 2011b; Malesza \& Ostaszewski, 2016). The significance of psychopathy contradicted previous findings on the non-significant relationship of psychopathy and problematic use of SNS (Kircaburun, et al., 2018). The inconsistency can be explained by the measures used. The Dirty Dozen (Jonason \& Webster, 2010) used by previous researchers to measure the traits of the Dark Triad (Kircaburun et al., 2018) has been criticized for its brevity that leads to omission of important content (Miller et al., 2012; see also Jones \& Paulhus, 2014). Research implicates for caution when utilizing the Dirty Dozen's (Jonason \& Webster, 2010) psychopathy subscale since it might attenuate correlations with psychopathic related constructs (Miller et al., 2012). Therefore, it is likely that the relationship of psychopathy and problematic SNS usage found previously (Kircaburun et al., 2018; Kircaburun et al., 2018b) was attenuated by the measure used. From a direct comparison, the SD3 (Jones \& Paulhus, 2014) used in the present research demonstrated better validity than the Dirty Dozen (Maples, Lamkin, \& Miller, 2014). This suggests that future research should consider the psychometrics of the measures used to assess the Dark Triad traits. Narcissism is often linked to self-promotional features on SNS (Fox \& Rooney, 2015; Garcia \& Sikström, 2014) that are vaguely represented by SNS addiction (Andreassen \& Pallesen, 2014; LaRose et al., 2010). Hence, the link between narcissism and SNS addiction has been portrayed as weak despite its significance (Andreassen et al., 2017). The present research found the correlation of .07 that was declared as not significant for narcissism and SNS addiction, which is slightly larger than the effect size of .06 found by Andreassen et al. (2017). Hence, the large sample size involved in the respective research may have inflated the link of SNS addiction and narcissism (Andreassen et al., 2017). Alternatively, the weak correlation of narcissism and SNS addiction can be accounted by the facets of narcissism. The narcissism subscale of the SD3 (Jones \& Paulhus, 2014) used in the present research reflects on the grandiose sense of self (Maples et al., 2014), which is similar to the Narcissistic Personality Inventory-16 (NPI-16; Ames, Rose, \& Anderson, 2006) used in Andreassen et al.'s (2017) research. Therefore, the link of grandiose narcissism and SNS addiction has been portrayed as weak. The significant correlation found previously (Kircaburun et al., 2018; Kircaburun et al., 2018b) was derived from the narcissism subscale of the Dirty Dozen (Jonason \& Webster, 2010) that reflects on both grandiose and vulnerable narcissism (Maples et al., 2014). Hence, it is likely that problematic SNS usage such as SNS addiction relates better to the vulnerable aspect of narcissism (Casale et al., 2016). Individuals with high Machiavellianism trait may prefer other forms of social network or interaction to achieve their goals (Fox \& Rooney, 2015). Moreover, individuals with salient features of Machiavellianism possess greater self-monitoring as an effort to disguise their manipulative tendencies (Abell \& Brewer, 2014). In this light, these individuals are less likely to be impulsive (Jones \& Paulhus, 2011a). With the absence of poor self-control that is central to the development of SNS addiction (Błachnio \& Przepiorka, 2016b), the trait of Machiavellianism did not correlate significantly with SNS addiction.

The present research found that high level of openness predicted lesser risk of SNS addiction, which is akin to previous findings (e.g. Andreassen et al., 2013; Błachnio \& Przepiorka, 2016a). It was also revealed that the trait of openness to new experience is protective against negative outcomes. Specifically, high degree of openness is 
known to reduce the risk of mortality (Ferguson \& Bibby, 2012; Jonassaint et al., 2007; Turiano, Sprio, \& Mroczek, 2012) as well as the likelihood to develop physical ailment (Israel et al., 2014). Similarly, individuals with high degree of openness tend to possess higher stress tolerance (Oswald et al., 2006; Williams, Rau, Cribbet, \& Gunn, 2009). In light of these findings, the measured trait of openness may be protective against SNS addiction. Of the five broad domains, low level of Agreeableness indicates for saliency of the Dark Triad traits (Muris, Merckelbach, Otgaar, \& Meijer, 2017; O'Boyle, Forsyth, Banks, Story, \& White, 2015). The present research replicated similar findings, except for narcissism that was not significantly correlated with Agreeableness. This can be accounted by the weak link of Agreeableness and narcissism (Muris et al., 2017; O'Boyle et al., 2015). Additionally, the measure utilized to assess the dark traits might further weakened the relationship between Agreeableness and narcissism. It was indicated that the effect sizes that reflect on the strength of the relationships of the Five-Factor model and the Dark Triad traits were larger when the dark traits were measured by the original measures (e.g. Mach-IV, Christie \& Geis, 1970; NPI-16, Ames et al., 2006; Psychopathy Checklist-Revised, Hare, 2003; see Muris et al., 2017). Therefore, the SD3 (Jones \& Paulhus, 2014) utilized in the present research may have attenuated the correlation coefficients, and thus, further reduce the weak link of narcissism and Agreeableness.

The present results supported that the inclusion of the Dark Triad traits contributed additional variance in the prediction of SNS addiction after controlling the Five-Factor model. This suggests that the Five-Factor model did not exhaust the variance in the measured SNS addiction entirely, leaving some additional variance to the Dark Triad. The present results are consistent with previous research that supported the significance of the Dark Triad after controlling the broad five domains in predicting perceived male attractiveness (Carter et al., 2014) and social values (Kajonius et al., 2015). This is an indication that the Five-Factor model does not reflect entirely on human personality, and the inclusion of the Dark Triad can extend the inadequacy (Veselka et al., 2011; Veselka et al., 2012). Therefore, the effects exerted by the Dark Triad traits on SNS addiction are independent of the Five-Factor model. The present findings also supported that the broad five domains of the Five-Factor model are lacking the required specificity to predict specific behaviours (Hough, 1992; McAdams, 1992) such as SNS addiction.

The findings obtained in the present research further expand the existing literature by focusing on the conceptual links of the traits measured. In relation to this, the present research revealed that other traits such as psychopathy of the Dark Triad are also influential even though some of the traits covered by the Five-Factor model have been significantly associated with SNS addiction. The measured psychopathy was found as the most influential predictor of SNS addiction due to its conceptual link with impulsivity. Additionally, the importance of the conceptual links of the measured traits and SNS addiction is further illuminated by the illustrated relationships. Specifically, some traits may increase vulnerability towards SNS addiction such as psychopathy that predicted SNS addiction positively, whereas some traits can be protective against SNS addiction as illustrated by the Openness to Experience that predicted SNS addiction negatively. In this light, it is recommended for future research to consider the conceptual link and to be more selective with the traits that will be used to predict SNS addiction. Moreover, the present results have supported that the Five-Factor model has limited influence in predicting SNS addiction (Amichai-Hamburger \& Vinitzky, 2010; Ross et al., 2009). Apart from that, the small effect sizes accounted by the Five-Factor model supports the recommendation to explore the significance of other personality traits (Ross et al., 2009; Skues et al., 2012). Therefore, the present findings suggest that further exploration with the Five-Factor model will only fixate the literature of SNS addiction.

One of the limitations of the present research is its inability to infer for causality due to the correlational design employed. Moreover, it is important to note that the generalizability of the results is limited due to the diverse and unequal demographics as well as the small number of student sample. In addition, the small effect sizes from the hierarchical regression show the need to expand the investigation on the conceptual link of SNS addiction with other personality traits. The use of concise measures of the Dark Triad, such as the SD3 (Jones \& Paulhus, 2014), affect the results by attenuating the effect sizes. Hence, future research should measure the traits of the Dark Triad with the original measures. Due to the conciseness of the SD3 (Jones \& Paulhus, 2014), the present research could only measure a fragment of the Dark Triad traits while these traits may be multifaceted (see Furnham, Richards, \& Paulhus, 2013). Thus, it is also imperative for future research to assess the role of different facets of the Dark Triad traits (e.g. primary psychopathy, secondary psychopathy) in shaping SNS addiction.

In summary, the present research concludes that the measured psychopathy of the Dark Triad is the most influential predictor of SNS addiction. It is also concluded that the Dark Triad traits accounted for more specificity 
compared to the Five-Factor model in the prediction of SNS addiction. Therefore, this further supports the recommendation of exploring traits other than the Five-Factor model.

\section{References}

Abell, L., \& Brewer, G. (2014). Machiavellianism, self-monitoring, self-promotion and relational aggression on Facebook. Computers in Human Behavior, 36, 258-262. https://doi.org/10.1016/j.chb.2014.03.076

Ames, D. R., Rose, P., \& Anderson, C. P. (2006). The NPI-16 as a short measure of narcissism. Journal of Research in Personality, 40, 440-450. https://doi.org/10.1016/j.jrp.2005.03.002

Amichai-Hamburger, Y., \& Vinitzky, G. (2010). Social network use and personality. Computers in Human Behavior, 26, 1289-1295.

Andreassen, C. S., Griffiths, M. D., Gjertsen, S. R., Krossbakken, E., Kvam, S., \& Pallesen, S. (2013). The relationships between behavioral addictions and the five-factor model of personality. Journal of Behavioral Addiction, 2, 90-99. https://doi.org/10.1556/JBA.2.20 13.003

Andreassen, C. S., Pallesen, S., \& Griffiths, M. D. (2017). The relationship between addictive use of social media, narcissism, and self-esteem: Findings from a large national survey. Addictive Behaviors, 64, 287-293.

https://doi.org/10.1016/j.addbeh.2016.03.006

Andreassen, C. S., Torsheim, T., Brunborg, G. S., \& Pallesen, S. (2012). Development of a Facebook Addiction Scale. Psychological Reports, 110, 501-517. https://doi.org/10.2466/02.09.18.PRO.110.2.501517

Andreassen, S. C., \& Pallesen, S. (2014). Social network site addiction: An overview. Current Pharmaceutical Design, 20, 4053-4061.

Benet-Martinez, V., \& John, O. P. (1998). Los Cinco Grandes across cultures and ethnic groups: Multitrait multimethod analyses of the Big Five in Spanish and English. Journal of Personality and Social Psychology, 75, 729750.

Błachnio, A., \& Przepiorka, A. (2016a). Personality and positive orientation in Internet and Facebook addiction. An empirical report from Poland. Computers in Human Behavior, 59, 230-236.

https://doi.org/10.1016/j.chb.2016.02.018

Błachnio, A., \& Przepiorka, A. (2016b). Dysfunction of self-regulation and self-control in Facebook addiction. Psychiatric Quarterly, 87, 493-500. https://doi.org/10.1007/s11126-015- 9403-1

Błachnio, A., Przepiorka, A., \& Pantic, I. (2016). Association between Facebook addiction, self-esteem and life satisfaction: A cross-sectional study. Computers in Human Behavior, 55, 701-705.

https://doi.org/10.1016/j.chb.2015.10.026

boyd, d. m., \& Ellison, N. (2007). Social network sites: Definition, history, and scholarship. Journal of ComputerMediated Communication, 13, 210-230. https://doi.org/10.1111/j.1083- 6101.2007.00393.x

Buckels, E. E., Trapnell, P. D., \& Paulhus, D. L. (2014). Trolls just want to have fun. Personality and Individual Differences, 67, 97-102. https://doi.org/10.1016/j.paid.2014.01.016

Buffardi, L. E., \& Campbell, W. K. (2008). Narcissism and social networking web sites. Personality and Social Psychology Bulletin, 34, 1303-1314. https://doi.org/10.1037/t00001-000

Caci, B., Cardaci, M., Scrima, F., \& Tabacchi, M. E. (2017). The dimensions of Facebook addiction as measured by Facebook Addiction Italian Questionnaire and their relationships with individual differences. Cyberpsychology, Behavior, \& Social Networking, 20, 251-258. https://doi.org/10.1089/cyber.2016.0073 
Carter, G. L., Campbell, A. C., \& Muncer, S. (2014). The dark triad personality: Attractiveness to women.

Personality and Individual Differences, 56, 57-61. https://doi.org/10.1016/j.paid.2013.08.021

Casale, S., Fioravanti, G., \& Rugai, L. (2016). Grandiose and vulnerable narcissists: who is at higher risk for social networking addiction?. Cyberpsychology, Behavior, \& Social Networking, 19, 510-515.

https://doi.org/10.1089/cyber.2016.0189

Chabrol, H., van Leeuwen, N., Rodgers, R., \& Séjourné, N. (2009). Contributions of psychopathic, narcissistic, Machiavellian, and sadistic personality traits to juvenile delinquency. Personality and Individual Differences, 47, 734-739. https://doi.org/10.1016/j.paid.2009.06.020

Christie, R., \& Geis, F. (1970). Studies in Machiavellianism. New York: Academic Press.

Crysel, L. C., Crosier, B. S., \& Webster, G. D. (2013). The Dark Triad and risk behavior. Personality and Individual Differences, 54, 35-40. http://dx.doi.org/10.1016/j.paid.2012.07.029

Dalbudak, E., Evren, C., Aldemir, S., \& Evren, B. (2014). The severity of Internet addiction risk and its relationship with the severity of borderline personality features, childhood traumas, dissociative experiences, depression and anxiety symptoms among Turkish university students. Psychiatry Research, 219, 577-582.

https://doi.org/10.1016/j.psychres.2014.02.032

Dean, A. C., Altstein, L. L., Berman, M. E., Constans, J. I., Sugar, C. A., \& McCloskey, M. S. (2013). Secondary psychopathy, but not primary psychopathy, is associated with risky decision-making in noninstitutionalized young adults. Personality and Individual Differences, 54, 272-277. https://doi.org/10.1016/j.paid.2012.09.009

Elphinston, R. A., \& Noller, P. (2011). Time to face it! Facebook intrusion and the implications for romantic jealousy and relationship satisfaction. Cyberpsychology, Behavior, and Social Networking, 14, 631-635. https://doi.org/10.1089/cyber.2010.0318

Ferguson, E., \& Bibby, P. A. (2012). Openness to experience and all-cause mortality: A meta-analysis and requivalent from risk ratios and odds ratios. British Journal of Health Psychology, 17, 85-102. https://doi.org/10.1111/j.20448287.2011.02055.x

Fox, J., \& Rooney, M. C. (2015). The Dark Triad and trait self-objectification as predictors of men's use and selfpresentation behaviors on social networking sites. Personality and Individual Differences, 76, 161-165. https://doi.org/10.1016/j.paid.2014.12.017

Furnham, A., Richards, S. C., \& Paulhus, D. L. (2013). The Dark Triad of personality: A 10 year review. Social and Personality Psychology Compass, 7, 199-216. https://doi.org/10.1111/spc3.12018

Garcia, D., \& Sikström, S. (2014). The dark side of Facebook: Semantic representations of status updates predict the Dark Triad of personality. Personality and Individual Differences, 67, 92-96.

https://doi.org/10.1016/j.paid.2013.10.001

Goodboy, A. K., \& Martin, M. M. (2015). The personality profile of a cyberbully: Examining the Dark Triad. Computers in Human Behavior, 49, 1-4. https://doi.org/10.1016/j.chb.2015.02.052

Hare, R. D. (2003). The psychopathy checklist - Revised manual ( $2^{\text {nd }}$ ed.). Toronto: Multi-Health Systems.

Hong, F. Y., Huang, D. H., Lin, H. Y., \& Chiu, S. L. (2014). Analysis of the psychological traits, Facebook usage, and Facebook addiction model of Taiwanese university students. Telematics and Informatics, 31, 597-606.

https://doi.org/10.1016/j.tele.2014.01.001

Hough, L. M. (1992). The 'Big Five' personality variables-construct confusion: Description versus prediction. Human Performance, 5, 139-155. https://doi.org/10.1080/08959285.1992.9667929 
Israel, S., Moffitt, T. E., Belsky, D. W., Hancox, R. J., Poulton, R., Roberts, B., . . Caspi, A. (2014). Translating personality psychology to help personalize preventive medicine for young adult patients. Journal of Personality and Social Psychology, 106, 484-498. https://doi.org/10.1037/a0035687

John, O. P., Donahue, E. M., \& Kentle, R. L. (1991). The Big Five Inventory--Versions 4a and 54. Berkeley, CA: University of California.

Jonason, P. K., \& Tost, J. (2010). I just cannot control myself: The Dark Triad and self-control. Personality and Individual Differences, 49, 611-615. https://doi.org/10.1016/j.paid.2010.05.031

Jonason, P. K., \& Webster, G. D. (2010). The dirty dozen: A concise measure of the dark triad. Psychological Assessment, 22, 420-432. https://doi.org/10.1037/a0019265

Jonassaint, C. R., Boyle, S. H., Williams, R. B., Mark, D. B., Siegler, I. C., \& Barefoot, J. C. (2007). Facets of openness predict mortality in patients with cardiac disease. Psychosomatic Medicine, 69, 319-322.

https://doi.org/10.1097/PSY.0b013e318052e27d

Jones, D. N., \& Figueredo, A. J. (2013). The core of darkness: Uncovering the heart of the Dark Triad. European Journal of Personality, 27, 521-531. https://doi.org/10.1002/per.1893

Jones, D. N., \& Paulhus, D. L. (2011a). The role of impulsivity in the Dark Triad of personality. Personality and Individual Differences, 51, 679-682. http://dx.doi.org/10.1016/j.paid.2011.04.011

Jones, D. N., \& Paulhus, D. L. (2011b). Differentiating the Dark Triad within the interpersonal circumplex. In L. M. Horowitz \& S. Strack (Eds.), Handbook of interpersonal psychology: Theory, research, assessment, and therapeutic interventions (pp. 249-269). New York, NY: Wiley \& Sons.

Jones, D. N., \& Paulhus, D. L. (2014). Introducing the Short Dark Triad (SD3): A brief measure of dark personality traits. Assessment, 21, 28-41. https://doi.org/10.1177/1073191113514105

Kajonius, P. J., Persson, B. N., \& Jonason, P. K. (2015). Hedonism, achievement, and power: Universal values that characterize the Dark Triad. Personality and Individual Differences, 77, 173-178.

https://doi.org/10.1016/j.paid.2014.12.055

Kennedy, P. (1992). A guide to econometrics. Oxford: Blackwell.

Kircaburun, K., Demetrovics, Z., \& Tosuntaş, Ş. B. (2018). Analyzing the links between problematic social media use, Dark Triad traits, and self-esteem. International Journal of Mental Health and Addiction. Advanced online publication. https://doi.org/10.1007/s11469-018-9900-1

Kircaburun, K., Jonason, P. K., \& Griffiths, M. D. (2018a). The Dark Tetrad traits and problematic online gaming: The mediating role of online gaming motives and moderating role of game types. Personality and Individual Differences, 135, 298-303. https://doi.org/10.1016/j.paid.2018.07.038

Kircaburun, K., Jonason, P. K., \& Griffiths, M. D. (2018b). The Dark Tetrad traits and problematic social media use: The mediating role of cyberbullying and cyberstalking. Personality and Individual Differences, 135, 264-269. https://doi.org/10.1016/j.paid.2018.07.034

Koc, M., \& Gulyagci, S. (2013). Facebook addiction among Turkish college students: The role of psychological health, demographic, and usage characteristics. Cyberpsychology, Behavior, \& Social Networking, 16, 279-284. https://doi.org/10.1089/cyber.2012.0249

LaRose, R., Kim, J. \& Peng, W. (2010). Social networking: Addictive, compulsive, problematic, or just another media habit? In Z. Papacharissi (Ed.), A networked self: Identity, community, and culture on social network sites (pp. 59-81). New York, NY: Taylor \& Francis. 
Malesza, M., \& Ostaszewski, P. (2016). Dark side of impulsivity-Associations between the Dark Triad, self-report and behavioral measures of impulsivity. Personality and Individual Differences, 88, 197-201.

https://doi.org/10.1016/j.paid.2015.09.016

Maples, J. L., Lamkin, J., \& Miller, J. D. (2014). A test for two brief measures of the Dark Triad: The Dirty Dozen and Short Dark Triad. Psychological Assessment, 26, 326-331. https://doi.org/10.1037/a0035084

McAdams, D. P. (1992). The five-factor model in personality: A critical appraisal. Journal of Personality, 60, 329361. https://doi.org/10.1111/j.1467-6494.1992.tb00976.x

McCain, J. L., Borg, Z. G., Rothenberg, A. H., Churillo, K. M., Weiler, P., \& Campbell, W. K. (2016). Personality and selfies: Narcissism and the Dark Triad. Computers in Human Behavior, 64, 126-133.

https://doi.org/10.1016/j.chb.2016.06.050

Miller, J. D., Few, L. R., Seibert, L. A., Watts, A., Zeichner, A., \& Lynam, D. R. (2012). An examination of the Dirty Dozen measure of psychopathy: A cautionary tale about the costs of brief measures. Psychological Assessment, 24, 1048-1053. https://doi.org/10.1037/a0028583

Muris, P., Merckelbach, H., Otgaar, H., \& Meijer, E. (2017). The malevolent side of human nature: A meta-analysis and critical review of the literature on the Dark Triad (narcissism, Machiavellianism, and psychopathy). Perspectives on Psychological Science, 12, 183-204. https://doi.org/10.1177/1745691616666070

O'Boyle, E. H., Forsyth, D. R., Banks, G. C., Story, P. A., \& White, C. D. (2015). A meta-analytic test of redundancy and relative importance of the Dark Triad and Five-Factor Model of personality. Journal of Personality, 83, 644664. https://doi.org/10.1111/jopy.12126

Ong, E. Y., Ang, R. P., Ho, J., Lim, J. C., Goh, D. H., Lee, C. S., \& Chua, A. Y. (2011). Narcissism, extraversion and adolescents' self-presentation on Facebook. Personality and Individual Differences, 50, 180-185. https://doi.org/10.1016/j.paid.2010.09.022

Oswald, L. M., Zandi, P., Nestadt, G., Potash, J. B., Kalaydjian, A. E., \& Wand, G. S. (2006). Relationship between cortisol responses to stress and personality. Neuropsychopharmacology, 31, 1583-1591.

https://doi.org/10.1038/sj.npp.1301012

Pabian, S., De Backer, C. J., \& Vandebosch, H. (2015). Dark Triad personality traits and adolescent cyberaggression. Personality and Individual Differences, 75, 41-46. https://doi.org/10.1016/j.paid.2014.11.015

Paulhus, D. L., \& Williams, K. M. (2002). The Dark Triad of personality: Narcissism, Machiavellianism, and psychopathy. Journal of Research in Personality, 36, 556-563. http://dx.doi.org/10.1016/S0092-6566(02)00505-6

Raskin, R. N., \& Terry, H. (1988). A principal component analysis of the narcissistic personality inventory and further evidence of its construct validity. Journal of Personality and Social Psychology, 54, 890-902.

https://doi.org/10.1037/0022-3514.54.5.890

Ross, C., Orr, E. S., Sisic, M., Arseneault, J. M., Simmering, M. G., \& Orr, R. R. (2009). Personality and motivations associated with Facebook use. Computers in Human Behavior, 25, 578-586.

https://doi.org/10.1016/j.chb.2008.12.024

Skues, J. L., Williams, B., \& Wise, L. (2012). The effects of personality traits, self-esteem, loneliness, and narcissism on Facebook use among university students. Computers in Human Behavior, 28, 2414-2419.

https://doi.org/10.1016/j.chb.2012.07.012

Stead, R., Fekken, G. C., Kay, A., \& McDermott, K. (2012). Conceptualizing the Dark Triad of personality: Links to social symptomatology. Personality and Individual Differences, 53, 10231028.

https://doi.org/10.1016/j.paid.2012.07.021 
Trumello, C., Babore, A., Candelori, C., Morelli, M., \& Bianchi, D. (2018). Relationship with parents, emotion regulation, and callous-unemotional traits in adolescents' internet addiction. BioMed Research International, 2018, 1-10. https://doi.org/10.1155/2018/7914261

Turiano, N. A., Sprio, A., \& Mroczek, D. K. (2012). Openness to experience and mortality in men: Analysis of trait and facets. Journal of Aging and Health, 24, 654-672. https://doi.org/101177/0898264311431303

Veselka, L., Schermer, J. A., \& Vernon, P. A. (2011). Beyond the Big Five: The Dark Triad and the Supernumerary Personality Inventory. Twin Research and Human Genetics, 14, 158-168. https://doi.org/10.1375/twin.14.2.158

Veselka, L., Schermer, J. A., \& Vernon, P. A. (2012). The Dark Triad and an expanded framework of personality. Personality and Individual Differences, 53, 417-425. https://doi.org/10.1016/j.paid.2012.01.002

Wang, C. W., Ho, R. T., Chan, C. L., \& Tse, S. (2015). Exploring personality characteristics of Chinese adolescents with internet-related addictive behaviors: Trait differences for gaming addiction and social networking addiction. Addictive Behaviors, 42, 32-35. https://doi.org/10.1016/j.addbeh.2014.10.039

Williams, P. G., Rau, H. K., Cribbet, M. R., \& Gunn, H. E. (2009). Openness to Experience and stress regulation. Journal of Research in Personality, 43, 777-784. https://doi.org/10.1016/j.jrp.2009.06.003

Wilson, K., Fornasier, S., \& White, K. M. (2010). Psychological predictors of young adults' use of social networking sites. Cyberpsychology, Behavior, \& Social Networking, 13, 173-177. https://doi.org/10.1089/cyber.2009.0094

\section{Correspondence to:}

Soon Li Lee

School of Liberal Arts \& Sciences, Faculty of Social Sciences \& Leisure Management

Taylor's University Lakeside Campus

Jalan Taylors 1

Subang Jaya 47500

Malaysia

Email: soonli.lee(at)taylors.edu.my

Editorial record: First submission received on April 26, 2018. Revisions received October 16,2018, and November 27, 2018. Accepted for publication on January 2, 2019.

\section{About Author}

Dr. Lee Soon Li (Ph.D. Monash University Malaysia, 2017) is a lecturer at Taylor's University Lakeside Campus. His research areas include the effects of media use on psychological well-being, the influence of personality on media use, and psychometrics. 